Ethology / Éthologie

\title{
Emergence and dispersal relative to natal nest in the digger wasp Stizus continuus (Hymenoptera: Crabronidae)
}

\author{
Carlo Polidori ${ }^{\mathrm{a}, *}$, Irene Giordani ${ }^{\mathrm{a}}$, Pablo Mendiola ${ }^{\mathrm{b}}$, Josep D. Asís ${ }^{\mathrm{c}}$, José Tormos ${ }^{\mathrm{c}}$, Jesús Selfa ${ }^{\mathrm{b}}$ \\ ${ }^{a}$ Dipartimento di Biologia, Sezione di Zoologia e Citologia, Università degli Studi di Milano, Via Celoria, 26, 20133 Milan, Italy \\ ${ }^{\mathrm{b}}$ Departament de Zoologia, Universitat de València, c/Dr. Moliner, 50, 46100, Burjassot, València, Spain \\ ' Unidad de Zoología, Facultad de Biología, Universidad de Salamanca, 37071 Salamanca, Spain
}

\section{A R T I C L E I N F O}

\section{Article history:}

Received 22 October 2009

Accepted after revision 24 November 2009

Available online 20 January 2010

\section{Keywords:}

Emergence

Nest establishment

Territory establishment

Digger wasp

Philopatry

\begin{abstract}
A B S T R A C T
The position of the emerging point has rarely been investigated as a factor possibly affecting the future nest settlement behaviour in Hymenoptera, in particular within nest aggregations. We studied the emergence and dispersion patterns of the digger wasp Stizus continuus. Individuals emerged daily in clumped patterns, possibly revealing a certain synchrony of emergence from the same nests, and protandry appeared both at seasonal and daily level. Differences between the number of females that nested relatively close or far from their emergence holes $(\mathrm{EH})$ were either significant or not, depending on the year, and observed dispersal distances from the natal nests did not differ from those obtained by random simulations. By contrast, females nested close to the nearest conspecific nest. Size did not affect the dispersion patterns. EH are thus not important cues for nest establishment, and conspecific nests are probably the key cue for nest-founding females. In addition, males did not prefer to establish territories close to their natal nest.

(c) 2009 Académie des sciences. Published by Elsevier Masson SAS. All rights reserved.
\end{abstract}

\section{Introduction}

Dispersal behaviour is an important determinant of many basic ecological patterns and processes [1]. In particular, natal dispersal, i.e., the net movement of an individual from its birthplace to the site of first reproduction, largely governs the dynamics and genetic structure of populations $[2,3,4]$. In bees, for example, different dynamics of natal dispersal may produce strongly structured populations [5] or almost completely unstructured populations (panmixia) [6]. Linked to natal dispersal is philopatry, i.e., the tendency of animals to remain at certain locations or to return to them [7], which can be exhibited by both sexes and can influence spatial characteristics of populations such as location and density [1].

\footnotetext{
* Corresponding author.

E-mail address: carlo.polidori@unimi.it (C. Polidori).
}

Despite there being much information available in literature about the general trend of ground-nesting Hymenoptera returning to their natal nesting site to establish new nests $[8,9]$, natal dispersal is still poorly studied in these insects, both within and between populations $[10,11]$. In substance, we know that philopatry, at a population-level, is widespread in both solitary and social nest-building Hymenoptera, but little is known on individual choice of nest site, in particular relative to the natal nest locations [12]. Emergence patterns are also little known, both at a temporal and, in particular, at a spatial scale [13]. This scarcity of investigations contrasts to the repeatedly suggested hypothesis that philopatry may have been an important factor which promoted the evolution of sociality in some lineages of bees and wasps, through the formation of long-living nest aggregations $[14,8,9]$, and consequently the increase of inbreeding and likelihood of encounters with near relatives $[15,16]$.

Among the factors believed to be important in promoting philopatry in Hymenoptera, at least two have 
been confirmed: habitat imprinting, or more recently called "natal habitat preference induction" [17]; and social intra-specific attraction [11]. Both factors deal with the fact that newly born individuals use cues of their natal site which are good indicators of its quality at the moment of settling: in the first case, these are environmental features, while in the second one, these are the successful nests established by conspecific individuals. Moreover, these two factors are not necessarily mutually exclusive, and could be both at work but at different spatial scales: for example, females may remain in the general natal area for nesting because of the adequate quality of the substrate and because such a kind of substrate is patchy in the environment, while within a nest aggregation, a female may tend to nest closer than expected by random choice to active nests of provisioning conspecifics [11].

From this point of view, in ground-nesting Hymenoptera, one cannot exclude that the position of the emergence point (hereafter "emergence hole" [EH]), which corresponds to the position on the soil surface of the brood cell in the mother's nest, may also have an effect on the subsequent dispersal decision. In groundnesting bees and wasps, EH position is directly spatially linked to the place where the successful development occurred, so it may represent a good indicator of the quality of substrate; at small scales, this cue would be efficient in avoiding to nest in unknown, potentially less adequate, areas, given that an entire nest aggregation is unlikely to be identical concerning environmental features such as soil softness, humidity and vegetation cover $[18,19,10]$.

However, the position of the exact emerging point, and not only of the general emerging area, has rarely been considered as a possible factor influencing the nest-settlement behaviour in bees and wasps. A positive influence (e.g. preference to settle close to $E H$ ) was shown in a ground-nesting social sweat bee [12] and in Polistes social wasps $[20,21]$; in some lineages (e.g. Cerceris digger wasps and Lasioglossum digger bees), an extreme case of such influence, namely the re-use of the emerging burrow (i.e. absence of dispersal), evolved [14,22].

The present study primarily focuses on the emergence and dispersion patterns of newly-eclosed females relative to their emergence points in the solitary digger wasp, Stizus continuus (Klug) (Crabronidae). In this species, females preferentially tend to dig close to conspecific active (still provisioned) nests, producing clumped patterns of nests that are thus the result of social attraction rather than simply the response to a limitation of available substrate [11]. However, if the EH is used as a cue, a given wasp could balance two attractions (emergence point versus conspecific nests) by choosing to nest near to a conspecific nest in a small area including its $\mathrm{EH}$. We addressed this question by marking and monitoring recently emerged females. We evaluated also the emergence and dispersal patterns of males of this species, studying in particular where males prefer to establish territories in relation to the position of their $\mathrm{EH}$.

\section{Materials and methods}

\subsection{Study area and study organism}

The study area, a coastal salt marsh with damp sandy soil, is located in the Albufera National Park, near Valencia (Spain). Characteristics of the observed nesting area of S. continuus, about $300 \mathrm{~m}^{2}$ in extent, are described in detail in Polidori et al. [11]. At this site, S. continuus shows two generations per year, with wasps active from middle of June to end of September.

The nesting cycle of $S$. continuus is summarized in Fig. 1 $[11,23,24]$. Males and females emerged from the underground nests breaking the soil surface (Fig. 1a), creating the $\mathrm{EH}$. These are monitored frequently by mate-searching males (Fig. 1b), which engage in fights to obtain access to emerging virgin females (Fig. 1c). Once mated (Fig. 1d), females dig their underground nests (Fig. 1e, f) and fill them with grasshopper prey to feed the larvae. The brood emerges in a second generation or enters diapause and emerges the following year.

\subsection{Emergence patterns}

As in Polidori et al. [11], the nesting area was divided in $233 \mathrm{~m} \times 3 \mathrm{~m}$-quadrats in order to facilitate the monitoring of wasps and the recording of spatial data (see below). The 23 quadrats were patrolled during the morning (from 7.00 to 12.00) (solar hours), when most emergences were observed in past studies on this population [23,11], between 20 July and 8 August 2003, between 20 July and 15 August 2004 and between 25 July and 20 August of 2006 (emergence of the second generation for all these years) and in June-August 2008 (both first [15 June-6 July] and second [28 July-20 August] generations). In 2008, the two generations were separated by 21 days of null emergence.

In 2003, we monitored each day, for the first 20 days of emergence of the second generation, the nesting area in search of new $\mathrm{EH}$, with the purpose to record their position and day of opening. A total of $253 \mathrm{EH}$ were marked (in 19 days, because one day, there was a rainfall), and their coordinates (error of $\pm 0.5 \mathrm{~cm}$ ) were recorded in a Cartesian system as in Polidori et al. [11]. Moreover, we excavated at the end of the nesting season (September) four nests, in order to obtain the distance between brood cells and the distance between the cells and the entrance of the nest (then used indirectly to approximately associate the $\mathrm{EH}$ of the same nests, see below).

In 2004, 2006 and 2008, every day at early morning, from five to 10 meshes of $1 \mathrm{~m} \times 1 \mathrm{~m}$ were placed on the ground before starting to patrol the area, in order to capture newly emerging wasps if the observers were in other zones of the nesting area.

When an emerging female or male was detected (directly while breaking the soil surface from inside, creating the typical $\mathrm{EH}$, or under a mesh close to a new $\mathrm{EH}$ ), it was marked with individual combination of colours on the thorax, their head width was measured to the nearest $0.02 \mathrm{~mm}$ with a digital calliper (only in 2008) and then it was released; the EH was also marked with a pin coloured 

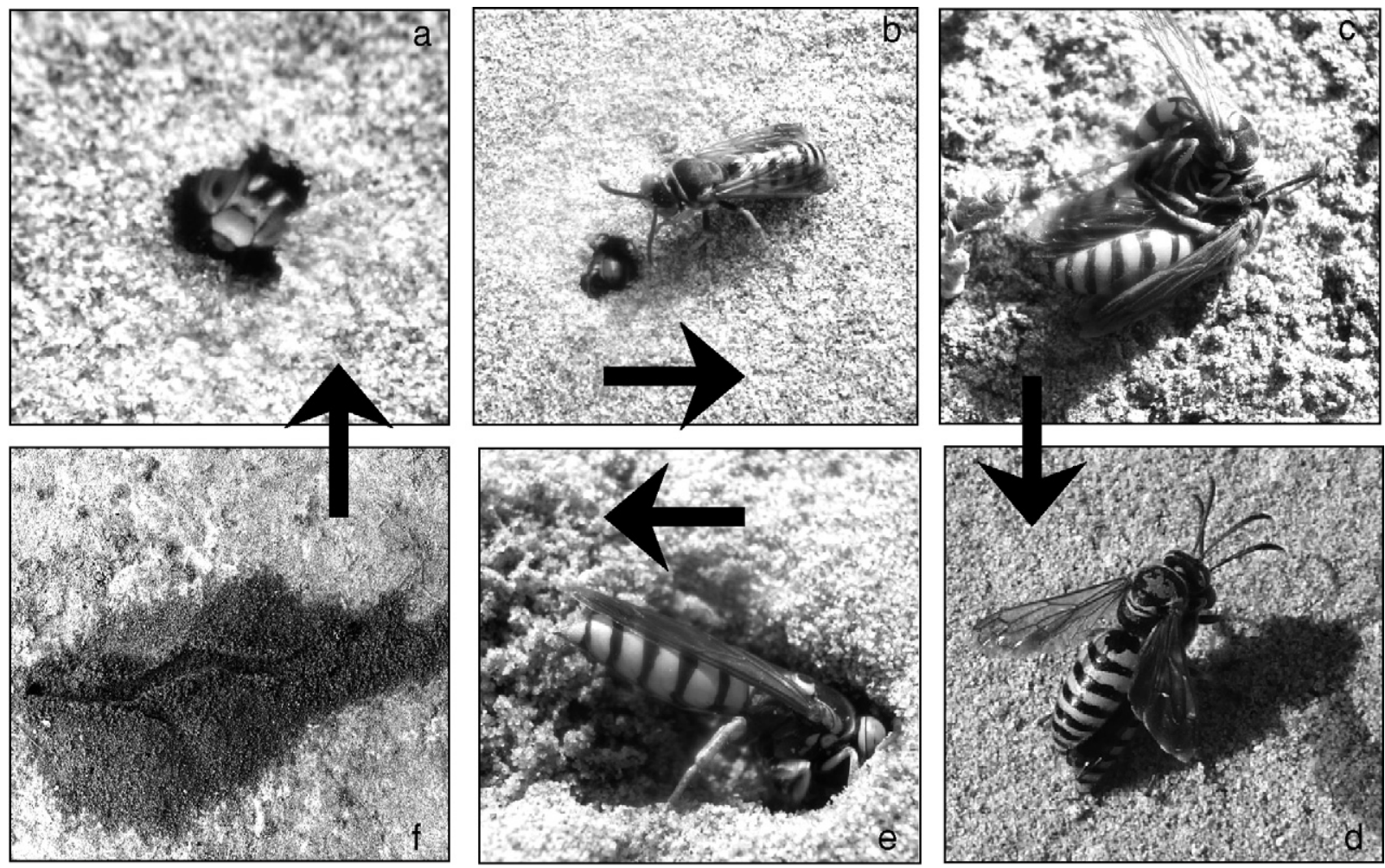

Fig. 1. Schematic representation of the nesting cycle of $S$. continuus: a: a female breaks the soil surface while emerging; b: a male guards an EH recently opened by an emerging female; c: males fight to gain a copula with a virgin female; d: a male mounts a recently emerged female; e: a mated female digging its nest; f: aspect of an almost completely provisioned nest (nest entrance on the left).

as the individual thorax. We marked 53 females in 2004, 30 females in 2006 and, in 2008, 15 males and 23 females in the first generation and 37 males and 21 females in the second one. For each emerging individual the following variables were recorded: date, hour, sex, head width (only in 2008) and position of the emerging hole.

\subsection{Dispersal patterns}

After emergence, females mate before digging the nest [9]. In 2004, 2006 and 2008, we monitored the area from the day after the emergence to the day we discovered the nest of each marked female, and marked the nest entrance with a coloured stick (same combination as the wasp thorax); in 2008, the coordinates of the $\mathrm{EH}$ and the nests were recorded (as above), and the distance between them (dispersal distance, DD) was calculated $( \pm 0.5 \mathrm{~cm})$. We then generated the dispersal distance distribution (DDD). The distance $( \pm 0.5 \mathrm{~cm})$ between the nest of the female and the nearest (active) one was also recorded. In 2004 to 2006, we used a different method: when we discovered the nest of a marked female, we recorded if the female dug its nest in the same quadrant of the $\mathrm{EH}$, in an adjacent one or in any other one of the nesting area. This method was also used additionally in 2008.

In 2008, we also monitored the spatial distribution of males upon emergence. We recorded:
- if the marked male was re-captured in the area immediately after emergence (same day) or later;

- if the male became the owner of a territory including its EH (same quadrat) or not (in an adjacent one or in any other one in the nesting area).

For males, it was not possible to calculate exactly the distances between the $\mathrm{EH}$ and their territories because of their size, about 200 to $400 \mathrm{~cm}^{2}$ on average [23]; however, we calculated the distance between the emerging points and the centre of the sub-quadrat $(1.5 \mathrm{~m} \times 1.5 \mathrm{~m})$ including the territory (named DDt, and the corresponding distribution DDDt).

These distributions (DDD and DDDt) are subject to sampling bias resulting from the finite size of the study site; the probability of detecting dispersal decreases with distance, and movements of a given distance from an $\mathrm{EH}$ near the boundary of the site are less likely to be detected than those of the same distance from a nest near the centre. However, because we are working at a small scale (within aggregation) and because previous studies suggest that females and males tend to stay inside their natal aggregation upon emergence [23,11], we probably mostly prevented this bias. In any case, in order to detect possible drifts of newly emerged individuals among aggregations, we also monitored, at interval of 5 to 10 days, two other aggregations placed at about 50 to $100 \mathrm{~m}$ from the studied 
one. No other aggregations of $S$. continuus were discovered at larger distances (up to $500 \mathrm{~m}$ of radius from the main aggregation).

Thus, data from 2003 served to study the spatial patterns of emergence, those from 2004 and 2006 for studying dispersal of females, and those from 2008 both for studying the temporal patterns of emergence and for studying dispersal behaviour of both males and females.

\subsection{Statistical analysis}

To look for seasonal and daily protandry, we used the two-sample Kolmogorov-Smirnov test.

We studied the spatial patterns of emergence calculating the nearest neighbour distance of each EH (NND), and then applying the single component test of Clark and Evans [25] (after Donnelly's edge-effect corrections [26]) which indicates deviation from randomness in one of two possible directions, regular or clumped (one-tailed test). To look for a relationship between the day of emergence and the NND of EH (and their clustering pattern, i.e., the value obtain from Clark and Evans' test), we used a Pearson correlation test.

We then evaluated, with the data from nest excavations, the NND of the brood cells, once projected on the surface ("converting" their position to that of the corresponding $\mathrm{EH}$ ), and we used the mean NND as the cut-off value to roughly determine if two EH likely belong to the same nest. We used also the position of the nests of the first generation (published in Polidori et al. [11]) to look at possible clear associations between nests and $\mathrm{EH}$ of the second generation.

To verify if wasps (both males and females) equally dispersed in the three categories (same quadrat of the EH, an adjacent one or in any another one of the nesting area), we used a $\chi^{2}$-test separately for each year. To test if average DD differed from the average NND of each nest, we used parametric paired comparison of means (Student's $t$ test). To test if a female wasp nested at a random distance from the $\mathrm{EH}$, we used a simulation program (www.randomizer.org [Social Psychology Network]): for each female, we asked the program to simulate 1000 random distances from the $\mathrm{EH}$, taking into account the maximum distance the wasp could reach staying in the aggregation area (i.e., not dispersing towards other nesting aggregations or in not yet colonized areas). We used the map of vegetation in the nest aggregation recorded in 2003 [11] to determine the areas where nests could not be established (because of vegetation bushes) (the vegetation distribution did not change from 2003 to the time of this study), and to calculate the maximum distance theoretically possible for nest establishment for each dispersal event. We then compared the observed and simulated mean DDs with a paired Student' $t$ test, and we also contrasted the observed DDD against a normal distribution with a one-sample Kolmogorov-Smirnov test. Because the error of such distances for males was large $(1.5 \mathrm{~m})$, we did not use the simulation method for them, and to test if a male wasp established its territory at a random distance from the $\mathrm{EH}$, we compared the distribution of observed distances with a normal curve through a onesample Kolmogorov-Smirnov test.
In the text, average values are expressed together with their standard deviation.

\section{Results}

\subsection{Spatial patterns of emergence}

This point was studied in 2003. The value of NND for the EH ranged from 1 to $262.9 \mathrm{~cm}, 18.4 \pm 33.6 \mathrm{~cm}$ on average at the end of the 20 days. The value of NND ranged, on average, from $6.3 \pm 4.2$ to $75.6 \pm 80 \mathrm{~cm}$ for $\mathrm{EH}$ opening the same day ( $n=17$ days because in two days only one EH opened), and from $18.3 \pm 34.6$ and $75.6 \pm 80 \mathrm{~cm}$ per day (cumulative value per day) (Fig. 2a).

The EH patterns resulted highly clumped (c of Clark and Evans $<-1.96$ ). This was true both for all the mean NND values per day for EH opening on the same day (Fig. 2c) and for the whole $\mathrm{EH}$ distribution at the end of the 20 days ( $R c=0.38, c=-14.4)$. Also, in case of the cumulative mean NND values per day, a clumped distribution resulted for all the 20 days (Fig. $2 \mathrm{c}$ ).

The mean value of NND per day for EH opening on the same day linearly decreased with date $(r=-0.74, n=17$, $P<0.001$ ), while no trend was observed for the corresponding values of Clark and Evans' Rc across days ( $r=-0.19, n=17, P=0.46$ ) (Fig. 2a, c). On the other hand, when considering the cumulative mean values of NND per day, a negative trend resulted for both NND $(r=-0.78$, $n=19, P<0.001)$, and for Rc $(r=-0.80, n=19, P<0.001)$ across days (Fig. 2a, c). Moreover, there was a positive linear correlation between the EH's NND and the days from its opening to the opening of the nearest $\mathrm{EH}(r=0.33$, $n=252, P<0.001$ ), although the variance did not seem to be strongly explained by the independent variable (days).

From the nest excavation, we found a total of 16 brood cells belonging to four nests. The NND between the projections of the brood cells to the surface ranged from 3 to $23 \mathrm{~cm}, 10.4 \pm 5.7 \mathrm{~cm}$ on average, and the distance between the cells and the nest entrance was $54 \pm 10.4 \mathrm{~cm}$ on average. Assuming, although with rough approximation, that the cells with NND $<10.4 \mathrm{~cm}$ belong to the same nests, we had that $172 \mathrm{EH}$ out of 252 have their nearest $\mathrm{EH}$ from the same nest. Out of these 172, 130 (75\%) have their nearest $\mathrm{EH}$ opening their same day (98 out of 172) or in the following two days (32 out of 172). Overlapping the maps of EH and first generation's nests (we used the first 26 nests established to avoid confusion produced by increasing nest density, see [11]), it resulted that nest entrances fall into $\mathrm{EH}$ clusters or at a maximum distance of $54 \mathrm{~cm}$ from $\mathrm{EH}$ in 16 out of 26 cases (see some examples in Fig. 2b).

Considering altogether these analyses, $\mathrm{EH}$ seem to have opened in a strongly clumped pattern in particular if they opened in the same day or in very close days, and that individuals from the same nest were more likely to emerge closely in time (0 to 3 days).

\subsection{Temporal patterns of emergence and protandry}

This point was studied in 2008. The first male was recorded on the 15 June and the first female on the 24 June (first generation), while first males and females of second 


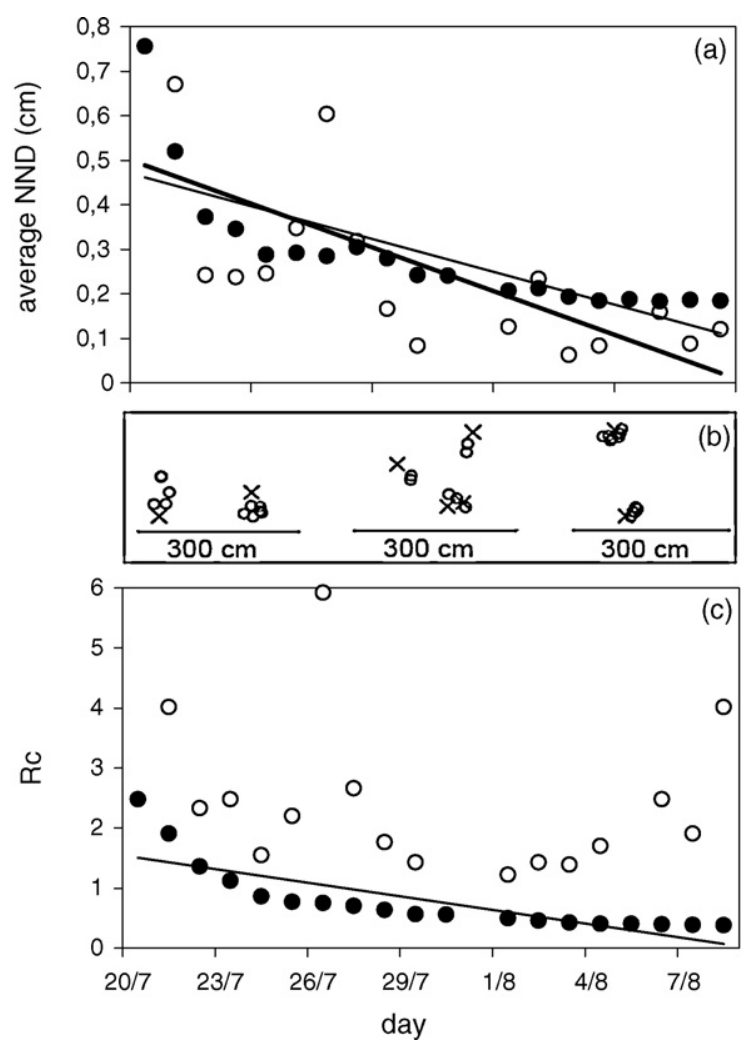

Fig. 2. Values of mean EHs' NND (a) and Clark and Evans'Rc (c) across the days of observation of emergence in 2003. Full dots and thin regression line refer to mean NND of EH opened in the same day, open dots and bold regression line refer to cumulative mean NND per day. In (b), some examples of clusters of EHs are shown (open dots), together with their associated nests of the first generation (crosses): from left to right: EHs opened from $20 /$ to $25 / 7$, EHs opened from $26 / 7$ to $1 / 8$, EHs opened from $2 / 8$ to $8 / 8$.

generation emerged on the 28 July and 1 August, respectively. At the seasonal level, the distributions of male and female emergences differed both in the first (Kolmogorov-Smirnov test, $D=0.68, n_{\mathrm{m}}=16, n_{\mathrm{f}}=23$, $P<0.001$ ), and the second generation (KolmogorovSmirnov test, $\left.D=0.56, n_{\mathrm{m}}=41, n_{\mathrm{f}}=21, P<0.001\right)$. Males seem to emerge earlier than females and reach their emerging peak before that of the females (Fig. 3a). Males were smaller than females both in the first (head widths: $4.25 \pm 0.38 \mathrm{~mm}$ vs $\left.5.26 \pm 0.43 \mathrm{~mm}, \mathrm{t}_{[35]}=6.50, P<0.001\right)$, and in the second generation $(4.51 \pm 0.38$ vs $4.90 \pm 0.44$, $\left.t_{[55]}=3.45, P=0.001\right)$. A negative linear correlation resulted between the size of females (head width) and the days of emergence in the first generation, although not much variance seems to be explained by the model $(r=-0.44$, $n=23, P=0.03)$. No linear trend resulted for female size across days in the second generation $(r=-0.03, n=19$, $P=0.9$ ) nor for male size across days in both generations $(r=0.01, n=14, P=0.92 ; r=0.10, n=38, P=0.53)$.

At a daily level, emergences were recorded from 7.30 to 11.30 (solar hours). No females emerged before 8.30 and no males after 11.00. Males emerged earlier in the day than females in the first generation (Kolmogorov-Smirnov test, $\left.D=0.63, n_{\mathrm{m}}=23, n_{\mathrm{f}}=14, P<0.001\right)$, but not in the second
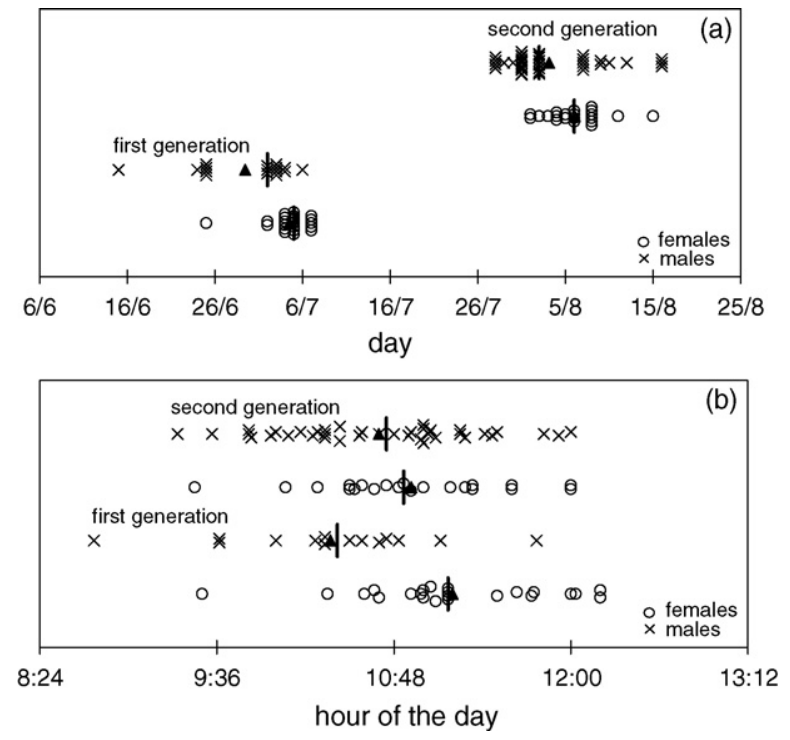

Fig. 3. Distribution of the 2008 emergence events of marked individuals across the days (a) and the hours (b) of observations. Full triangles: mean, short horizontal black lines: medians.

one (Kolmogorov-Smirnov test, $D=0.27, n_{\mathrm{m}}=38, n_{\mathrm{f}}=21$, $P=0.2$ ) (Fig. 3b). No correlation was observed between the size of individuals and the hour of emergence either in the first (females: $r=0.33, n=23, P=0.11$; males: $r=-0.24$, $n=13, P=0.41$ ) or in the second generation (females: $r=0.05, n=19, P=0.83$; males: $r=0.10, n=38, P=0.52$ ).

\subsection{Dispersion of females}

Females emerged quite slowly, taking from 10 minutes to about 30 minutes to completely break the soil surface and leave the EH. During such time, males (generally the territorial one and a variable number of intruders) aggregated around the $E H$, waiting for the female emergence. Once emerged, a female was violently harassed by the males, until the winner (usually the territory owner, which was also the largest one) successfully pre-mounted it, sometimes flying away with it to copulate in a safe place. At this point, females disappeared from the nesting site. Out of 44 marked females, 27 were seen again after emergence, and 24 established successfully their nests. Females re-appeared in the nesting site after a period of $2.73 \pm 1.72$ days from emergence day ( $n=24$, range $=1$ to 31 days). In particular, $52 \%$ of the females were re-captured in the area less than 2 days from emergence and the proportion of the females re-captured less than 4 days increased to $80 \%$. Only five females were re-captured after 7 to 31 days. The number of days separating the emergence and the nest establishment was slightly higher $(3.18 \pm 3.05$ days, $n=24$, range $=1$ to 31$)$. There is a strong correlation between the day of re-capture and that of nest establishment $(r=0.98, n=24, P<0.001)$; thus, the recapture alone seems a good predictor of the day of nest settlement.

The differences among the number of females that nested: 
Table 1

Number of marked individuals which nested (females) or established territories (males) in areas very close (same quadrat), relatively close (adjacent quadrat) or far (other quadrats) from their emergence holes. Also, there are shown the number of non-territorial marked males and the number of nonrecaptured marked individuals.

\begin{tabular}{lllccc}
\hline & Same quadrat & Adjacent quadrat & Other quadrats & Non-territorial (males) & Lost \\
\hline Females (2004) & 7 & 29 & 7 & - & 20 \\
Females (2006) & 9 & 11 & 5 & - & $2.24, P=0.52$ \\
Females (2008) & 2 & 7 & $14^{\mathrm{a}}$ & - & $22.51, P<0.001$ \\
Males (2008) & 5 & 6 & 8 & 6 & 20 \\
\hline
\end{tabular}

a Does not includes the only female whose nest was found in another nesting site. The $\chi^{2}$-test refers to the numbers in the first three columns.

- in the same quadrat of emergence;

- in an adjacent quadrat of the emergence one;

- in any other quadrats in the area, were either significant or not depending on the year (Table 1).

In 2004, there was no difference, in 2006 the females nested more often in a quadrat adjacent to the emergence one, and in 2008, they chose more often a quadrat other than that of emergence (Table 1 ). In addition, only one female was discovered to have established the nest in one of the two other patrolled nesting aggregations.

Nests were established by marked females in 2008 between $27 \mathrm{~cm}$ and $2040 \mathrm{~cm}$ from their $\mathrm{EH}$ ( $\mathrm{DD}=670.96 \pm 526.51$ on average, $n=25$ ) (Fig. 4), while the distance between the established nests and nearest (active) conspecific nests ranged from 10 to $400 \mathrm{~cm}$ $(79.56 \pm 86.26 \mathrm{~cm}$ on average, $n=25)$. The two average distances differed $\left(\mathrm{t}_{[24]}=-5.79, P<0.001\right)$, the distance to the nearest nest being much shorter.

DDD followed a normal distribution (one-sample Kolmogorov-Smirnov, $D=0.15, n=25, P=0.56$ ) (Fig. 5a). Moreover, no differences resulted between the average observed DD and the average simulated DD (1000 simulations/wasp) (paired $t_{[24]}=-1.2, P=0.24$ ).

Size of females was not correlated with their DD $(r=0.24, n=42, P=0.09$ ), and DD neither increased nor decreased with day in both generations (first generation: $r=0.16, n=15, P=0.55$; second generation: $r=0.16, n=10$, $P=0.66)$.

\subsection{Dispersion of males}

A total of 52 males were marked upon emergence, and 27 were re-captured in the area, after 1 to 11 days from emergence ( $3.11 \pm 2.77$ days on average, $n=27$ ). Out of these 27, 18 established territories, i.e., they were observed persistently (at least for 2 consecutive days from their first re-capture) to patrol for $\mathrm{EH}$ and often guarding (staying on the ground) freshly opened $\mathrm{EH}$ in relatively small areas of about 200 to $400 \mathrm{~cm}^{2}$. Territorial males commonly engaged in fights with intruder males, which entered their territories or tried to harass freshly emerged females. During fights, they could also lose the territory; however, the important datum for this study was the position of the first territory established after emergence. On the contrary, non-territorial males were observed in different zones of the nesting area each day, without staying more than few hours in a fixed area. Moreover, non-territorial males were not continuously recorded during several days in the area, presumably because they were looking for virgin females on plants around the nesting site.
Most of 2008's territorial males established the territory between 100 and $800 \mathrm{~cm}$ from their EH (approximate distance, see methods); in only two cases, the distance was much higher (1300 and $1700 \mathrm{~cm}$ ) (Fig. 6). The average DDt was $500 \pm 400 \mathrm{~cm}(n=18)$. DDDt did not differ from a normal distribution (one-sample Kolmogorov-Smirnov, $\mathrm{D}=0.24, n=18, P=0.2$ ) (Fig. 5b).

The difference among the number of males that established the territory:

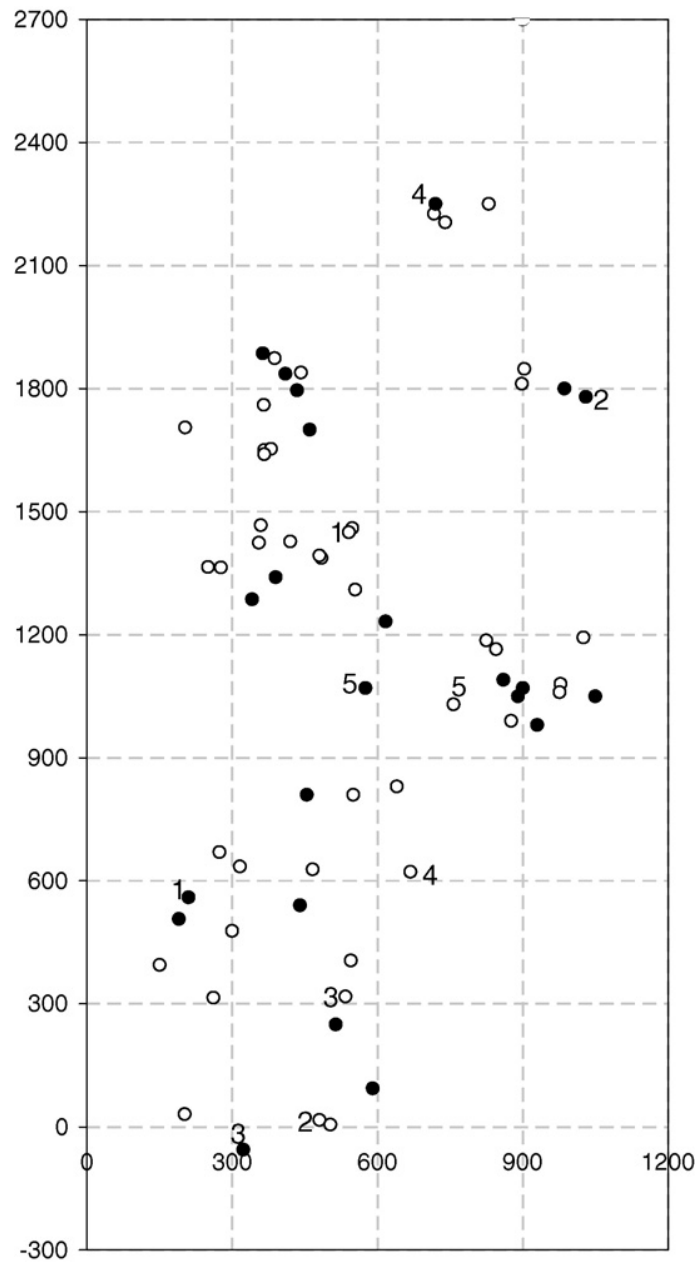

Fig. 4. Map of emergence holes (EH) (open dots) and of nests (full dots) recorded for the marked females in 2008. Examples of the connection between $\mathrm{EH}$ and nest are shown for some wasps by the same numbers. 

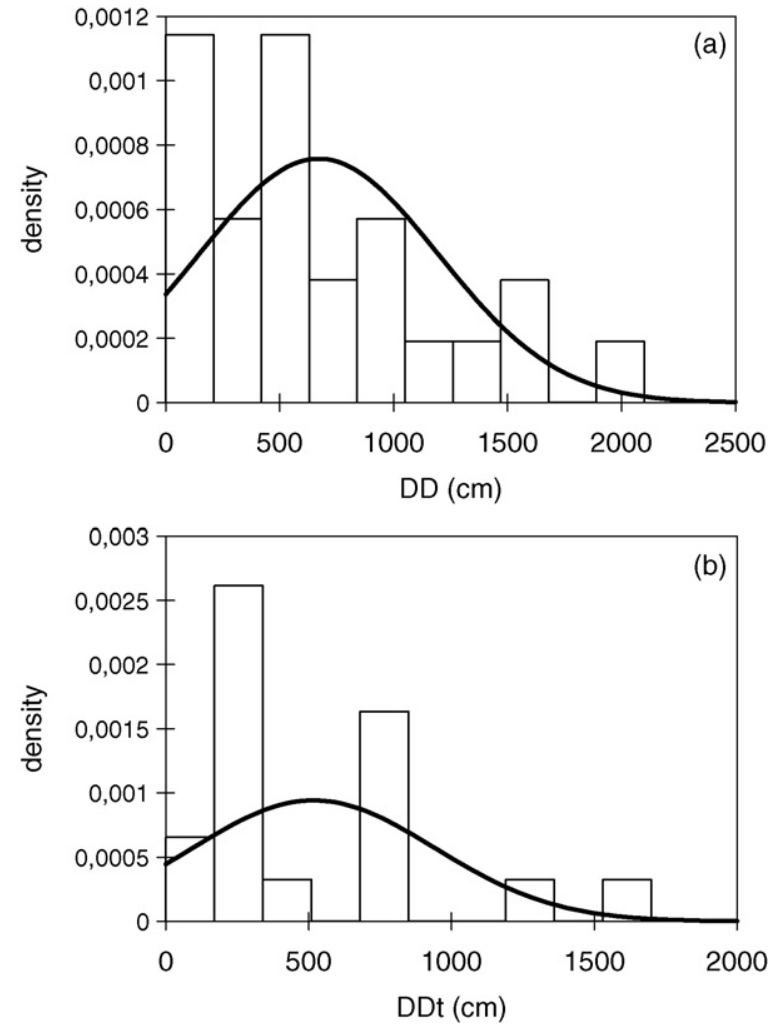

Fig. 5. Distribution of the 2008 dispersal distances for marked individuals; a: distances between emerging holes and established nests (DD) of females; b: distances between emerging holes and established territories (DDt) of males. Normal curves fitting with the data are shown.

- in the same quadrat of emergence;

- in quadrat adjacent to the emergence one;

- in any other quadrats in the area, was not significant (Table 1).

Size of males was not correlated with their DDt $(r=0.05$, $n=52, P=0.4)$.

\section{Discussion}

\subsection{Emergence patterns}

Our results show that EH were highly clumped in the nesting site on each day of emergence, and that this pattern was more and more strong towards the end of the period, when probably most of the individuals were emerged [11]. As far as we know, no other previous studies on digger wasps or bees evaluated the spatial patterns of EH. The observed pattern is certainly related to the clusters of brood cells of each nest, in an aggregation where nests themselves are also generally clumped [11]. Polidori et al. [11] found that nests appeared also clumped in particular at the beginning of the nesting season, in particular when considering only the "active nests" and not all the dug nests (cumulative). Although our method to associate the $\mathrm{EH}$ to the same or different nests is

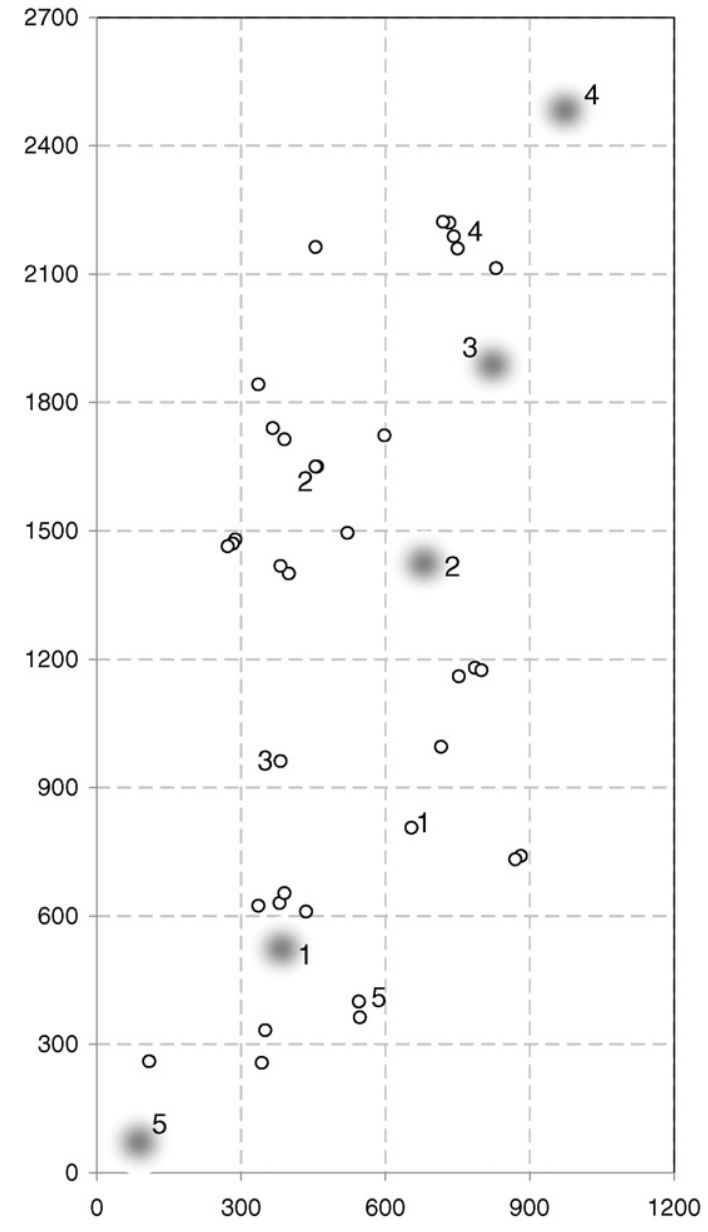

Fig. 6. Map of emergence holes (EH) (open dots) and of territories (shaded grey circles) recorded for the marked males in 2008. Examples of the connection between $\mathrm{EH}$ and territory are shown for some wasps by the same numbers. Note that the location of the territories is approximated to a sub-quadrat of $1.5 \mathrm{~m} \times 1.5 \mathrm{~m}$ (see text).

approximate, we think that, to some extent, results suggests that close $\mathrm{EH}$ (coming presumably from the same nests) open in a more or less synchrony. On the other hand, such synchrony was not always found: $25 \%$ of $\mathrm{EH}$, based on NND cut-off, would have their nearest EH from the same nests, but the temporal gap between the pairs of openings was 4 to 15 days (median $=8$ ). This may reflect the differential timing of emergence of males and females. In fact, from 2008 data (see also below), we know that about 1 week (median) separated the emergence of males and females in both generations.

The analysis on the temporal emerging patterns showed a clear protandry. Males emerged earlier than females both at a seasonal (in both generations) and daily level (in the first generation).

Seasonal protandry is widespread among solitary aculeate hymenopterans $[27,28,29]$, and our results confirmed what was observed in earlier studies on the same $S$. continuus population $[23,11]$. It is believed that in insects with monandrous females, the seasonal protandry is advantageous to males because it maximizes the 
number of females that could be inseminated, and, at the same time, it reduces the risk for females to die before being mated [30,31]. On the other hand, intrasexual variation of timing of emergence seems basically to depend on wasp size, the date on which the egg was laid, and rearing conditions [32]. In a study on the partially bivoltine mud-dauber wasp, Trypoxylon politum Say (Crabronidae), adult size was correlated with emergence date for overwintering wasps, but not for direct developing individuals [30]. Something similar, but with an opposite trend, occurred in our population: the size of females of $S$. continuus negatively correlated with date of emergence, but only in the first generation (whose pupae overwintered). The reason of such difference in the direction of the correlation between the two species remains obscure, and probably depends on a number of non-controlled variables.

The daily protandry has been documented in a variety of insects, such as some butterflies [33] and parasitoid wasps [34], but has less frequently been recorded for aculeate hymenopterans $[23,35]$, probably because studies devoted to this aspect are scarcer, rather than due to an effective rarity of this phenomenon. Asís et al. [23] reported for $S$. continuus daily curves of emergences for females alone and females and males together and, although no test was performed, they suggest daily protandry. This study is thus the first showing statistical evidence of daily protandry in this digger wasp.

Daily protandry may have the same advantages than the seasonal one: it could be a strategy which assures even to the first emerged females in a given day to find a partner to mate $[33,34,35]$. In fact, male territorial activity is concentrated between 8.00 and 11.00 in the morning $[23,11]$, and females would increase in this way the probability to be detected by males.

As far as we know, the only other species of groundnesting hymenopteran for which daily protandry was found is the solitary digger bee Amegilla dawsoni (Rayment) (Apidae) [35]. Similarly to what occurs in $S$. continuus, the proportion of $A$. dawsoni females surpassed that of males only from 11.00 in the morning, then increasing until the early afternoon (when emergences stopped); moreover, in this bee, smaller males emerged earlier than larger ones, and the author suggests that this could represents a strategy for small males to obtain a copula, given that they are strongly disadvantaged relative to large males while competing for virgin females [35]. By contrast, we did not found any effect of S. continuus size on the time of emergence. Alcock [35] also noted that the earlier emergence of males than females in A. dawsoni may actually require that the generally smaller males, absorbing heat more quickly, overcome a thermal handicap, but he thought this is unlikely because of the size of this bee, which almost certainly guarantees endothermy. For the same reason, we can exclude that thermal constrains affect emergence time of a large wasp like S. continuus; supporting this idea, males were smaller than females in the both generations, but we found daily protandry only in the first one. On the other hand, data from the meteorological station of Valencia (http:// www.ceam.es/ceamet/) gave for summer 2008 a lower mean daily temperature for June $\left(20-22^{\circ} \mathrm{C}\right)$ than for July and August $\left(24-26^{\circ} \mathrm{C}\right)$, so that an effect of temperature on the separation in the timing of emergence between males and females could not be discarded. This hypothesis needs to be tested recording the air and soil temperatures at the wasps' nesting site during the emergence periods.

\subsection{Dispersal patterns}

Our results showed that females of $S$. continuus did not tend to establish their nests closer to their emerging point than expected by chance. This differs from what has been observed in other hymenopterans, both ground-nesting species and aerial-nesting species.

For example, in the ground-nesting social sweat bee Halictus rubicundus (Christ), foundresses overwinter far from the emergence site, but return there to establish the nests, typically at less than $50 \mathrm{~cm}$ from their $\mathrm{EH}$ [12].

In species which can re-use the emergence burrows (such as solitary wasps in the genus Cerceris or some social sweat bees in the genus Lasioglossum), this strategy may be generally preferred, both because in this way, the newlyborn females stay in the same valuable microhabitat where they developed and because they spend less time searching for a suitable site to nest $[22,14]$. In Cerceris arenaria (L.), in addition, those females which cannot reuse their natal nests prefer to occupy conspecific ones at about $1 \mathrm{~m}$ from it, in an area of about $1 \mathrm{~m} \times 10 \mathrm{~m}$ [14]. A similar case was found in Ceratina flavipes Smith (Apidae), a solitary bee which constructs nests in grass shoots. Solitary hibernants of this bee were found, in about $30 \%$ of cases, in reused nests, and the remaining females were seen to disperse in a relatively small area in the dune grassland around natal nests [36].

Short dispersal distances seem to occur also in social aerial-nesting Hymenoptera. Investigations on philopatry in Polistes wasps, for example, showed that foundresses coming back to their natal sites perched preferentially on fragments of their natal nest (attracted by natal nest hydrocarbons), and built their own nest close to it [20,21]; in another study, a large proportion of queens of Polistes riparius Sk. et S. Yamane and $P$. snelleni de Saussure nested in close proximity to their natal sites (although some did disperse over $100-300 \mathrm{~m}$, so that these species seem to have the potential for a long-distance dispersion) [37].

All these observations suggest that emerging points may be valuable cues for newly nesting hymenopteran females. In our case, however, the philopatric tendency seems to be strong at a larger scale, i.e. females rarely nested outside their natal nest aggregation. We found only one female which settled in a different nesting area, about $100 \mathrm{~m}$ from its natal one and this agrees to what recently reported in a previous study [11]. One notes, however, that in the present study, a substantial percentage of females marked upon emergence were not recaptured in any of the monitored nesting sites, while in 2003, this was a much rarer event [11]. Although we cannot exclude the possibility of a longer dispersal distance of these females, we think that this is unlikely, at least for most of them. First, no other suitable nesting site was found in about 500 m-radius area, excluding the two mentioned aggregations; if females 
drifted to new areas, they should have found two nesting sites that actually they ignored. Second, the wasps often establish their nests under bushes' edges, and this could complicate their discovering [11]. If, in 2008, females nested more often under bushes than in 2003, detection of nests would have been more difficult. Another hypothesis is that mortality upon emergence could have been higher in 2008 than in 2003. In any case, this does not affect our main conclusion, i.e., that $\mathrm{EH}$ position did not influence nest establishment, because we were primarily studying withinaggregation dispersal patterns, rather than drifting between nesting sites.

Long dispersal distances ( 8 to $300 \mathrm{~m}$ ) were also rarely recorded for females of the digger wasp Sphex ichneumoneus L., particularly towards the middle or the end of the season [18], and the author suggests that this occurred because of learning the location of emergence area. On the other side, long dispersal distances seem to be more common in some digger bees [38,6].

Why are $S$. continuus females not attracted by the position of their EH while deciding to settle?

The comparison between the mean DD and the mean nest-nest distance strongly suggests that this could be due to the strong intra-specific attraction: females would prefer to nest close to other, already provisioning, conspecifics. This could be even true considering that this kind of social attraction was already assessed for this species at the same nesting site [11]. Females, thus, could use other females as cues for the quality of the substrate, instead of employing the location of their own successful development.

There are, however, alternative, and non-mutually exclusive, hypotheses. For example, females of $S$. continuus could not be able to memorize correctly their EH while emerging, through orientation flights, i.e. those spiral-like, ascending flights above the nest which are important for bees and wasps to find their nests in subsequent visits [8]. In fact, emerging $S$. continuus females are immediately harassed by males, and they can not perform such orienteering behaviour. This problem would not exist for $H$. rubicundus (which nest very close to $\mathrm{EH}$ ) and $C$. arenaria (which even tend to re-use the natal burrow). In these species, in fact, females meet males to mate far from the nests $[12,14]$, and thus can readily orient themselves around the nest entrance upon emergence and memorize the $\mathrm{EH}$ position.

Similarily to females, but obviously for different reasons, $S$. continuus males were not influenced by their $\mathrm{EH}$ while establishing their territories. As for females, males seem to come back to the general emerging areas in search of virgin females, as no marked males were discovered in the other two monitored nest aggregations (although the proportion of lost marked individuals may suggest a general high mortality, as hypothesised for females). Territorial males established their territories randomly in the area. Later in the season, they appear concentrated more often in areas of higher densities of $\mathrm{EH}$ [23], probably because of particular cues emitted from females while emerging from underground (e.g. chemical volatiles, vibrations). Because males are the only ones, which largely determine variation of within-aggregation inbreeding (females mate before they disperse), the absence of a male EH-based attraction may reduce the probability of harrassing emerging sisters from the same nests the males have emerged, thus ultimately reducing inbreeding. In fact, in our study, only five (26\%) of territorial males established the territory in their emergence area (same quadrat). Assuming from a previous study that about $80 \%$ of females were inseminated by territorial males [23], one has that, in this study, only about four of them (21\% of territorial males and $16 \%$ of all re-captured males) would mate with a sister (because they established their territories in the same quadrat of emergence, where their sisters also emerged). This value is, moreover, probably overestimated, because males are unlikely to maintain one single territory throughout their life, so that this $16 \%$ of males would mate with sisters only if the territory is maintained during females' emergence. Then, most of the females in our study probably copulated with non-kins. On the other side, if there is a tendency, as we suggested here, to a synchronous emergence of individuals from the same nest, males, in particular at the beginning of the emergence period, could have a higher probablity to meet female relatives. It would be interesting, using molecular markers, to evaluate in future studies the population genetics in this species of digger wasp to address all these questions.

\section{Acknowledgement}

Thanks are due to the Ayuntamiento de Valencia and the Generalitat Valenciana for the permits necessary to carry out this work in a Nature Reserve. Francesca Soldati and Micol Montagna helped with field work. The research was partially supported by a grant from the Ministerio de Educación y Ciencia (Spanish Government) (CGL200602568). Experiments comply with the current Spanish law.

\section{References}

[1] J. Clobert, E. Danchin, A. Dhondt, J.D. Nichols, Dispersal, Oxford University Press, Oxford, 2001.

[2] M.L. Johnson, M.S. Gaines, Evolution of dispersal: theoretical models and empirical tests using birds and mammals, Annu. Rev. Ecol. Syst. 21 (1990) 449-480.

[3] M.C. Whitlock, Dispersal and the genetic properties of metapopulations, in : J.E. Clobert, A.A. Danchin, J.D. Dhondt, Nichols (Eds.), Dispersal, Oxford University Press, Oxford, 2001, pp. 273-282.

[4] G. Spong, S. Creel, Deriving dispersal distances from genetic data, Proc. R. Soc. Lond. B 268 (2001) 2571-2574.

[5] Z.Y. Shao, H.X. Mao, W.J. Fu, M. Ono, D.S. Wang, M. Bonizzoni, et al., Genetic structure of Asian populations of Bombus ignitus (Hymenoptera: Apidae), J. Heredity 95 (2004) 46-52.

[6] M. Beveridge, L.W. Simmons, Panmixia: an example from Dawson's burrowing bee (Amegilla dawsoni) (Hymenoptera: Anthophorini), Mol. Ecol. 15 (2006) 951-957.

[7] P.J. Greenwood, Mating systems, philopatry and dispersal in birds and mammals, Animal Behav. 28 (1980) 1140-1162.

[8] K.M. O'Neill, Solitary wasps. Behavior and natural history, Comstock Publishing Associates, Ithaca and London, 2001.

[9] H.E. Evans, K.M. O'Neill, The sand wasps. Natural history and behavior, Harvard University Press, Cambridge, MA, London, England, 2007.

[10] S.G. Potts, P. Willmer, Abiotic and biotic factors influencing nest-site selection by Halictus rubicundus, a ground-nesting bee, Ecol. Entomol. 22 (1998) 319-328.

[11] C. Polidori, P. Mendiola, J.D. Asís, J. Tormos, J. Selfa, F. Andrietti, Femalefemale attraction influences nest establishment in the digger wasp 
Stizus continuus (Hymenoptera: Crabronidae), Animal Behav. 75 (2008) 1651-1661.

[12] D. Yanega, Philopatry and nest founding in a primitively social bee, Halictus rubicundus, Behav. Ecol. Sociobiol. 27 (1990) 37-42.

[13] B.N. Danforth, Emergence dynamics and bet-hedging in a desert bee Perdita portalis, Proc. R. Soc. Lond. B 266 (1999) 1985-1994.

[14] C. Polidori, M. Casiraghi, M. Di Lorenzo, B. Valarani, F. Andrietti, Philopatry, nest choice, and aggregation temporal-spatial change in the digger wasp Cerceris arenaria (Hymenoptera: Crabronidae), J. Ethol. 24 (2006) 155-163.

[15] M.J. West-Eberhard, Polygyny and the evolution of social behavior in wasps, J. Kansas Entomol. Soc. 51 (1978) 832-856.

[16] P.F. Kukuk, P.C. Decelles, Behavioural evidence for population structure in Lasioglossum (Dialictus) zephyrum female dispersion patterns, Behav. Ecol. Sociobiol. 19 (1986) 42-50.

[17] J.M. Davis, J.A. Stamps, The effect of natal experience on habitat preferences, TREE 19 (2004) 411-416.

[18] H.J. Brockmann, Nest-site selection in the great golden digger wasp. Sphex ichneumoneus L. (Sphecidae), Ecol. Entomol. 4 (1979) 211-224.

[19] D.B. McCorquodale, Soil softness, nest initiation and nest sharing in the wasp, Cerceris antipodes (Hymenoptera:Sphecidae), Ecol. Entomol. 14 (1989) 191-196.

[20] P.T. Starks, Natal nest recognition in the paper wasp Polistes dominulus, Ann. Zool. Fennici 40 (2003) 53-60.

[21] A. Sumana, A.E. Liebert, A.S. Berry, G.T. Switz, C.M. Orians, P.T. Starks, Nest hydrocarbons as cues for philopatry in a paper wasp, Ethology 111 (2005) 469-477.

[22] S.F. Sakagami, K. Hoshikawa, H. Fukuda, Overwintering ecology of two social halictine bees. Lasioglossum duplex and L. problematicum, Res. Popul. Ecol. 26 (1984) 363-378.

[23] J.D. Asís, J. Tormos, S.F. Gayubo, Territorial dynamics and contest behaviour in the solitary wasp Stizus continuus (Hymenoptera: Apoidea: Crabronidae), Behaviour 143 (2006) 83-104.

[24] C. Polidori, P. Mendiola, J.D. Asís, J. Tormos, M.D. Garcia, J. Selfa, Predatory habits of the grasshopper-hunting wasp Stizus continuus (Hymenoptera: Crabronidae): diet preference, predator-prey size relationships and foraging capacity. J. Nat. Hist 43 (2009) 2985-3000.

[25] P.J. Clark, F.C. Evans, Distance to the nearest neighbour as a measure of spatial relationships in populations, Ecology 35 (1954) 445-453.
[26] K.P. Donnelly, Simulations to determine the variance and edge effect of total nearest-neighbour distance, in : I.R. Hodder (Ed.), Simulation methods in archaeology, Cambridge University Press, Cambridge, UK, 1978, pp. 91-95.

[27] H.E. Evans, M.J. West-Eberhard, The wasps, The University of Michigan Press, Ann Arbor (1970).

[28] J. Hastings, Protandry in western cicada killer wasps, (Sphecius grandis, Hymenoptera:Sphecidae): an empirical study of emergence time and mating opportunity, Behav. Ecol. Sociobiol. 25 (1989) 255260.

[29] R. Rust, Emergence patterns in the alkali bee, Nomia melanderi Cockerell 1906 (Hymenoptera: Halictidae): laboratory versus field, The Pan-Pac. Entomol. 83 (2007) 136-142.

[30] T. Fagerström, C. Wiklund, Why do males emerge before females? Protandry as a mating strategy in male and female butterflies, Oecologia 52 (1982) 164-166.

[31] C. Zonneveld, J.A.J. Metz, Models on butterfly protandry: virgin females are at risk to die, Theor. Pop. Biol. 40 (1991) 308-321.

[32] H.J. Brockmann, Variable Life-History Patterns in the Pipe-Organ Muddaubing Wasp, Trypoxylon politum (Hymenoptera: Sphecidae), J. Kansas Entomol. Soc. 77 (2004) 503-527.

[33] C. Wiklund, T. Fagerström, Why do males emerge before females? Oecologia 31 (1977) 153-158.

[34] J. Doyon, G. Boivin, Impact of the timing of male emergence on mating capacity of males in Trichogramma evanescens Westwood, BioControl 51 (2006) 703-713.

[35] J. Alcock, Small males emerge earlier than large males in Dawson's burrowing bee (Amegilla dawsoni) (Hymenoptera: Anthophorini), J. Zool. 242 (1997) 453-462.

[36] M. Kidokoro, T. Kikuchi, M. Hirata, Prehibernal insemination and short dispersal of Ceratina flavipes (Hymenoptera: Anthophidae) in northernmost Japan, Ecol. Res. 18 (2003) 99-102.

[37] S. Makino, S.K. Yamane, T. Sunose, S. Aoki, Dispersion distance of queens from natal sites in the two haplometrotic paper wasps Polistes riparius and P. snelleni (Hymenoptera: Vespidae), Res. Pop. Ecol. 29 (1987) 111-117.

[38] I. Bischoff, Population dynamics of the solitary digger bee Andrena vaga Panzer (Hymenoptera, Andrenidae) studied using mark-recapture and nest counts, Pop. Ecol. 45 (2003) 197-204. 